\title{
Non-vitamin K Oral Anticoagulants in Hypertrophic Cardiomyopathy Patients Undergoing Catheter Ablation of Atrial Fibrillation
}

Antonio Creta ${ }^{1}$, Ross J Hunter ${ }^{1}$, Mark J Earley ${ }^{1}$, Malcolm Finlay ${ }^{1}$, Mehul Dhinoja ${ }^{1}$, Simon

Sporton $^{1}$, Anthony Chow ${ }^{1}$, Saidi A Mohiddin ${ }^{1}$, Serge Boveda ${ }^{2}$, Pedro Adragao ${ }^{3}$, Zeynab Jebberi $^{2}$, Daniel Matos ${ }^{3}$, Richard J Schilling ${ }^{1}$, Pier D Lambiase ${ }^{1}$, Rui Providência ${ }^{1,4}$

${ }^{1}$ Barts Heart Centre, St. Bartholomew's Hospital, London, United Kingdom

${ }^{2}$ Clinic Pasteur of Toulouse, Toulouse, France

${ }^{3}$ Cardiology Department, Hospital de Santa Cruz, Lisbon, Portugal

${ }^{4}$ Institute of Health Informatics Research, University College of London, London, UK

Running title: hypertrophic cardiomyopathy and atrial fibrillation

Manuscript word count: 1929 words

\section{Corresponding author:}

Antonio Creta

Barts Heart Centre

St. Bartholomew's Hospital

West Smithfield

London EC1A 7BE

Tel: +442037658646

Email: creta.antonio@gmail.com 


\section{Abstract}

Introduction: Patients with hypertrophic cardiomyopathy (HCM) and atrial fibrillation (AF) require chronic anticoagulation due to a high thromboembolic risk. Evidence supporting use of non-vitamin $\mathrm{K}$ oral anticoagulants (NOACs) in patients with $\mathrm{HCM}$ remain sparse, and there are no data regarding the use of NOACs in HCM patients undergoing catheter ablation of AF. Methods: Observational non-randomised study in 4 European Centres. We aimed to investigate the safety and efficacy of NOACs compared with vitamin-K antagonists (VKAs) in patients with HCM undergoing catheter ablation for AF.

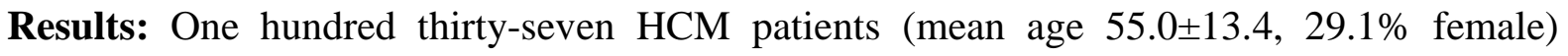
underwent 230 catheter ablations for $\mathrm{AF}(1.7 \pm 1.0$ per patient). A total of 55 patients $(39.4 \%)$ underwent 70 procedures $(30.4 \%)$ on NOAC, while the remaining were on VKA. Warfarin (97.6\%) and rivaroxaban (56.4\%) were the most frequently used agents in the respective groups. No procedure-related deaths were reported. We observed no significant difference in the rate of thromboembolism (VKA $0.6 \%$; NOAC $0 \%$; $=1.0$ ) or minor bleeding (VKA $0.6 \%$; NOAC $1.4 \% ; \mathrm{p}=0.54)$. There was a non-significant trend towards a lower incidence of major bleeding (VKA 6.8\%; NOAC 1.4\%; p=0.09).

Conclusion: Our preliminary data suggest that NOACs are at least as safe and effective as VKAs in patients with HCM undergoing catheter ablation for AF. However, these findings should be confirmed in a randomised fashion.

Key words: hypertrophic cardiomyopathy; atrial fibrillation; catheter ablation; warfarin; nonvitamin $\mathrm{K}$ oral anticoagulants. 


\section{Introduction}

Hypertrophic cardiomyopathy (HCM) is the most frequent monogenic cardiovascular disease and affects 1 out of every 500 individuals [1]. Atrial fibrillation (AF) is a common complication of HCM, with an estimated prevalence of $22.5 \%$ [1]. Given the high thromboembolic risk in HCM patients with concomitant AF, life-long oral anticoagulation is recommended, regardless of the $\mathrm{CHA}_{2} \mathrm{DS}_{2} \mathrm{VASc}$ score [2-3].

Non-vitamin K anticoagulants (NOACs) have emerged as a valid and more practical alternative to vitamin $\mathrm{K}$ antagonists (VKAs) [4]. Even though data supporting the use of NOACs in patients with HCM and AF are sparse, recent observational studies suggest that NOACs might be safely used in this population [5].

Catheter ablation is an established treatment for AF and is also used in subjects with HCM [1]. During and in the days to months immediately after the procedure patients are exposed to an increased risk of thromboembolism [6]. Complications can occur in up to a fifth of HCM patients undergoing AF ablation [7]. Although observational studies suggest that AF ablation can be safely performed in HCM patients on VKA [1], the safety and efficacy of such a procedure while on NOACs has not yet been established. The aim of this study was to address this knowledge gap.

\section{Methods}

Study design

Observational study in 4 European centres. We included all patients aged over 18 with confirmed diagnosis of $\mathrm{HCM}$ undergoing a catheter ablation for AF. According to the guidelines of the European Society of Cardiology [2], HCM was defined as a wall thickness $\geq 15 \mathrm{~mm}$ in one or more left ventricular myocardial segments (on either echocardiogram or cardiac magnetic resonance imaging) that is not explained solely by loading conditions. 
Participants needed to be on effective oral anticoagulation (VKA, apixaban, edoxaban, rivaroxaban, or dabigatran) for at least 30 days before the procedure to be considered for inclusion. Peri-procedure interruption or continuation of the oral anticoagulants, with or without heparin bridging, was based on the local protocol of each centre at the time of the ablation. All patients provided written informed consent prior to the procedure. The study complied with the Declaration of Helsinki and the research protocol was approved by the local ethics or audit committees.

\section{Catheter ablation}

Procedures were performed under sedation or general anaesthesia, according to each institution's protocol. Venous access was obtained via the femoral vein, with use of vascular ultrasound at operator's discretion. In the absence of patent foramen ovale, a single or dual transseptal puncture was performed under fluoroscopic guidance. Transesophageal echocardiography (TOE) was used based on operator preference. Patients received intravenous heparin to maintain an activated clotting time of 300-350 seconds. Pulmonary vein isolation was the main procedural endpoint, and was performed as a first step in all procedures. Additional substrate modification was at operator's discretion. Patients were evaluated before discharge, at 30-days, and 3-months after the procedure, additional visits and further testing were allowed in case of symptoms.

\section{Thromboembolic and bleeding events}

The following safety and efficacy endpoints were assessed [8]:

1. All-cause peri-procedural death.

2. Thromboembolism, which was defined as a composite of stroke, transient ischaemic attack (TIA), systemic or pulmonary embolism. A stroke was defined as a sudden focal 
neurological deficit of presumed cerebrovascular aetiology lasting for 24 hours, not due to another identifiable cause and confirmed by computed tomography or magnetic resonance imaging of the brain. If symptoms were short lasting $(<24 \mathrm{~h})$ and no evidence of necrosis was found on brain imaging, the event was considered to be a TIA. A systemic embolic event was defined as an abrupt vascular insufficiency associated with clinical or radiological evidence of arterial occlusion in the absence of another likely mechanism (e.g. atherosclerosis, instrumentation, or trauma). A pulmonary embolism was diagnosed when dyspnoea or other suggestive clinical presentation was accompanied by a confirmation of a new pulmonary perfusion or intra-luminal defect.

3. Major bleeding, which was defined as composite of cardiac tamponade, bleeding requiring intervention (e.g., either thrombin injection or surgery) or transfusion, massive haemoptysis, haemothorax, retroperitoneal bleeding, fatal bleed, or any other bleeding leading to or causing prolongation of hospitalisation.

4. Minor bleeding, which was defined as a composite of puncture site bleeding, thigh ecchymosis or haematoma, pericardial effusion with no haemodynamic compromise, minor gastrointestinal bleeding, epistaxis, or any bleeding treated conservatively with no need for transfusion, surgery, or prolonged hospitalization.

The criteria for definition of major or minor bleeding are strongly based on the recommendation from the International Society on Thrombosis and Haemostasis [9], but adapted for catheter ablation of AF [8].

\section{Statistical analysis}

The chi-square test and t-student test were used for comparison of categorical and continuous variables, respectively. Levene's test was used to check the homogeneity of variance; equivalent non-parametric tests were used when Kolmogorov-Smirnov was in favour of the 
absence of normal distribution. Results with $P<0.05$ were regarded as significant. PASW Statistics version 18.0 was used for descriptive and inferential statistical analysis.

\section{Results}

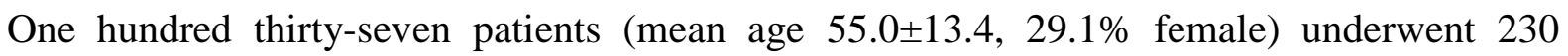
catheter ablations for $\mathrm{AF}(1.7 \pm 1.0$ per patient). A total of 55 patients $(39.4 \%)$ underwent 70 procedures $(30.4 \%)$ on NOAC, the remaining were ablated while on VKAs. Warfarin $(97.6 \%)$ and rivaroxaban $(56.4 \%)$ were the most frequently used agents in the respective groups. VKA interruption regimen with low-molecular weight heparin bridging was adopted in 56 catheter ablations (35\%). NOAC use was uninterrupted pre-procedure in all patients but one (no heparin bridging was performed either). Pre-procedural TOE was performed for 40 and 125 ablations in the NOAC and VKA group (57.1\% vs. $78.1 \%$, respectively; $\mathrm{p}<0.001) ; 3$ procedures in the VKA group were deferred due to the presence of intracardiac thrombus $(\mathrm{p}=0.55)$.

Most patients had paroxysmal AF (57.5\%) at baseline, and mean AF duration was $3.3 \pm 3.1$ years. Mean $\mathrm{CHA}_{2} \mathrm{DS}_{2} \mathrm{VASc}$ and HAS-BLED score were $1.5 \pm 1.5$ and $0.8 \pm 0.9$, respectively. As many as $10.4 \%$ had a history of stroke or TIA, and $3.6 \%$ was on concomitant single antiplatelet therapy. Mean left atrial diameter was $47 \pm 7 \mathrm{~mm}$.

Some differences were found at baseline population between the two groups: left ventricular ejection fraction, wall thickness and outflow tract gradient were higher in subjects on NOAC; patients on VKA more frequently presented with persistent AF or had history of previous surgical myectomy. Detailed baseline characteristics are reported in Table 1.

\section{Procedural outcomes}

The overall rate of complication was $9.3 \%$. No procedure-related deaths were reported. A low incidence of thromboembolism $(0.7 \%)$ was observed, with only one patient on uninterrupted 
VKA suffering from an ischemic stroke immediately after the ablation with minor neurological sequalae. No thromboembolic events were reported in the NOAC group.

There was a numerically higher rate of major bleeding with VKA versus NOAC (6.8\% vs. $1.4 \%$, respectively; $\mathrm{p}=0.09$ ); after excluding patients on interrupted VKA with heparin bridging the numerical difference was confirmed $(5.8 \%$ vs. $1.4 \%, \mathrm{p}=0.16)$. The overall rate of pericardial effusion requiring pericardiocentesis was $4.0 \%$, and was numerically higher in the VKA versus NOAC group ( $4.5 \%$ vs $1.4 \%$, respectively; $\mathrm{p}=0.11$ ). Puncture complications filling major bleeding criteria were observed in 3 patients $(1.3 \%)$ on VKA. The incidence of minor bleeding was low $(0.9 \%)$ and comparable between the two groups. These results are shown in Tables 3 and 4.

\section{Discussion}

Preliminary data from this multicentre study suggest that use of NOACs appears to be effective and safe in HCM patient undergoing catheter ablation of AF. The incidence of thromboembolic events was low with both VKA and NOAC. A non-significant but numerically higher rate of major bleedings and cardiac tamponade in patients on VKA versus NOAC was observed.

Several landmark trials have demonstrated that NOACs are at least as effective as VKA for prevention of thromboembolic events of AF [10-13]. However, no randomised data are available on the effectiveness of NOAC in the HCM population. Similar to our findings, four observational studies have suggested that NOACs, compared to VKA, are associated with a similar or lower rate of thromboembolic and bleeding events in subjects with HCM and AF [14-17]. Current HCM guidelines from the European Society of Cardiology suggest the use of NOACs as a second-line drugs in patient with concomitant AF [2]. According to the European Heart Rhythm Association 2018 Practical Guide on Oral Anticoagulants, HCM patients might be eligible for NOACs [4]. The 2014 American Heart Association/American College of 
Cardiology/Heart Rhythm Society guidelines for AF (confirmed in 2019) state that NOAC "might represent another option to reduce the risk of thromboembolic events, but data for patients with HCM are not available" $[3,18]$.

Catheter ablation for AF represents an effective treatment for symptomatic drug-refractory AF [19]. However, the intra- and post-procedural thromboembolic risk is not negligible and requires effective anticoagulation. In fact, both manipulation of the catheters and creation of lesions inside the left atrium can lead to local thrombus formation [6]. There is a significant body of evidence showing that NOACs can be safely used in patients undergoing catheter ablation of $\mathrm{AF}$, with a similar or lower rate of bleeding and thromboembolic complications compared to VKA [6]. The RE-CIRCUIT [20], VENTURE-AF [21] and AXAFA [22] trials have respectively demonstrated the safety and efficacy of uninterrupted dabigatran, rivaroxaban, and apixaban during catheter ablation of AF. However, patients with HCM were not represented in these trials. Data on catheter ablation of AF in HCM patients are still sparse, and only arising from small observational studies [1]. A systematic review and metanalysis from our group has shown that catheter ablation of AF appears to be safe in the HCM population, and might represent a valuable option despite a higher arrhythmia relapse rate compared to the general population [1].

To the best of our knowledge, we present the largest published series of HCM patients undergoing catheter ablation of AF, and this is the first study to investigate the effectiveness of NOACs in this very high-risk setting. We are not aware of other studies where NOACs have been used at the time of AF ablation in individuals with HCM.

Our findings are reassuring and add to the body of evidence suggesting that use of NOACs appears to be safe and effective in HCM patients with AF, with a risk profile which appears at least similar to VKAs. Of note, no intracardiac thrombus was identified in the 40 preprocedural TOEs in the NOAC group. Similarly, there were no embolic events in the NOAC 
group and major bleeding and cardiac tamponade were numerically lower compared to VKA. We believe our findings might have relevant clinical implications in HCM patients with AF elected for an ablative strategy as they ease some of the concerns regarding NOACs and the absence of data in this high-risk setting.

\section{Limitations}

Several limitations should be acknowledged. This was an observational and non-randomised study. Given the small sample size, this study was underpowered to demonstrate noninferiority of NOAC vs. VKA for most of the study comparisons (which referred to events with a rate $<10 \%$ ). However, our multicentre data constitute the largest cohort of HCM patients undergoing AF ablation, and this is the first study to investigate the use of NOAC in this setting. An interrupted oral anticoagulation strategy with heparin bridging is no longer the standard of care and was used in a few patients in this series. However, the observed numerical differences were maintained even in sub-analyses excluding such patients. We could not provide data on silent cerebral infarction, as patients did not routinely undergo brain magnetic resonance imaging post-ablation. Only a limited number of patients were on edoxaban or dabigatran.

\section{Conclusion}

Our preliminary data suggest that NOACs are as safe and effective compared to VKA in patients with HCM undergoing catheter ablation for AF. However, these findings should be confirmed in a randomised fashion.

Disclosures and Conflicts of Interest - AC has received educational grants from Boston Scientific and Abbott; RJS has had research agreements and speaker fees from Abbott, Medtronic, Boston Scientific, and Biosense Webster; PDL has received educational grants 
from Medtronic and Boston Scientific; MF has received speaker fees from Biotronik and Medtronic, and owns stocks of Epicardio ltd. All other authors have reported that they have no relationships relevant to the contents of this paper to disclose.

\section{Tables}

Table 1. Baseline characteristics of the study population

Table 2. Type of oral anticoagulant

Table 3. Efficacy and Safety Endpoints

Table 4. Subgroup analysis

\section{References}

[1] Providencia R, Elliott P, Patel K, McCready J, Babu G, Srinivasan N, Bronis K, Papageorgiou N, Chow A, Rowland E, Lowe M, Segal OR, Lambiase PD. Catheter ablation for atrial fibrillation in hypertrophic cardiomyopathy: a systematic review and meta-analysis. Heart 2016;102:1533-1543.

[2] Elliott P, Anastasakis A, Borger MA, Borggrefe M, Cecchi F, Charron P, Hagege AA, Lafont A, Limongelli G, Mahrholdt H, McKenna WJ, Mogensen J, Nihoyannopoulos P, Nistri S, Pieper PG, Pieske B, Rapezzi C, Rutten FH, Tillmanns C, Watkins H. 2014 ESC Guidelines on diagnosis and management of hypertrophic cardiomyopathy: the Task Force for the Diagnosis and Management of Hypertrophic Cardiomyopathy of the European Society of Cardiology (ESC). Eur Heart J. 2014;14;35:2733-2779.

[3] January CT, Wann LS, Alpert JS, Calkins H, Cigarroa JE, Cleveland JC Jr, Conti JB, Ellinor PT, Ezekowitz MD, Field ME, Murray KT, Sacco RL, Stevenson WG, Tchou PJ, Tracy CM, Yancy CW; ACC/AHA Task Force Members. 2014 AHA/ACC/HRS Guideline for the Management of Patients With Atrial Fibrillation. J Am Coll Cardiol. 2014;64;e1-e76. 
[4] Steffel J, Verhamme P, Potpara TS, Albaladejo P, Antz M, Desteghe L, Haeusler KG, Oldgren J, Reinecke H, Roldan-Schilling V, Rowell N, Sinnaeve P, Collins R, Camm AJ, Heidbüchel H; ESC Scientific Document Group. The 2018 European Heart Rhythm Association Practical Guide on the use of non-vitamin K antagonist oral anticoagulants in patients with atrial fibrillation. Eur Heart J. 2018 Apr 21;39(16):1330-1393.

[5] Zhou Y, He W, Zhou Y, Zhu W. Non-vitamin K antagonist oral anticoagulants in patients with hypertrophic cardiomyopathy and atrial fibrillation: a systematic review and metaanalysis. J Thromb Thrombolysis. 2019 Dec 2. doi: 10.1007/s11239-019-02008-3. [Epub ahead of print]

[6] Calkins H, Hindricks G, Cappato R, Kim YH, Saad EB, Aguinaga L, Akar JG, Badhwar V, Brugada J, Camm J, Chen PS, Chen SA, Chung MK, Nielsen JC, Curtis AB, Davies DW, Day JD, d'Avila A, de Groot NMSN, Di Biase L, Duytschaever M, Edgerton JR, Ellenbogen KA, Ellinor PT, Ernst S, Fenelon G, Gerstenfeld EP, Haines DE, Haissaguerre M, Helm RH, Hylek E, Jackman WM, Jalife J, Kalman JM, Kautzner J, Kottkamp H, Kuck KH, Kumagai K, Lee R, Lewalter T, Lindsay BD, Macle $\quad$ L, Mansour $\quad$ M, Marchlinski FE, Michaud GF, Nakagawa H, Natale A, Nattel S, Okumura K, Packer D, Pokushalov E, Reynolds MR, Sanders $\quad$ P, Scanavacca $\quad$ M, Schilling R, Tondo C, Tsao HM, Verma A, Wilber DJ, Yamane T. 2017 HRS/EHRA/ECAS/APHRS/SOLAECE Expert Consensus Statement on Catheter and Surgical Ablation of Atrial Fibrillation. Heart Rhythm 2017;14:e275-e444.

[7] Garg L, Sabzwari SRA, Akbar G, Ayele H, Agrawal S, Agarwal M, Gordon J, Dusaj R, Nazir T, Bozorgnia B, Martinez M. Outcomes of cateter ablation for atrial fibrillation in patients with hypertrophic cardiomyopathy. J Am Coll Cardiol. 2019;73;suppl 1;478 (abstract presented at the American Journal of Cardiology Congress 2019- 68th Annual Scientific Sessions) 
[8] Providência R, Marijon E, Albenque JP, Combes S, Combes N, Jourda F, Hireche H, Morais J, Boveda S. Rivaroxaban and dabigatran in patients undergoing catheter ablation of atrial fibrillation. Europace. 2014;16:1137-1144.

[9] Schulman S, Kearon C; Subcommittee on Control of Anticoagulation of the Scientific and Standardization Committee of the International Society on Thrombosis and Haemostasis. Definition of major bleeding in clinical investigations of antihemostatic medicinal products in non-surgical patients. J Thromb Haemost. 2005;3:692-694.

[10] Giugliano RP, Ruff CT, Braunwald E, Murphy SA, Wiviott SD, Halperin JL, Waldo AL, Ezekowitz MD, Weitz JI, Špinar J, Ruzyllo W, Ruda M, Koretsune Y, Betcher J, Shi M, Grip LT, Patel SP, Patel I, Hanyok JJ, Mercuri M, Antman EM. Edoxaban versus warfarin in patients with atrial fibrillation. $N$ Engl J Med. 2013;369:2093-2104.

[11] Granger CB, Alexander JH, McMurray JJV, Lopes RD, Hylek EM, Hanna M, Al-Khalidi HR, Ansell J, Atar D, Avezum A, Bahit MC, Diaz R, Easton JD, Ezekowitz JA, Flaker G, Garcia D, Geraldes M, Gersh BJ, Golitsyn S, Goto S, Hermosillo AG, Hohnloser SH, Horowitz J, Mohan P, Jansky P, Lewis BS, Lopez-Sendon JL, Pais P, Parkhomenko A, Verheugt FWA, Zhu J, Wallentin L. Apixaban versus warfarin in patients with atrial fibrillation. New Engl J Med. 2011;365:981-992

[12] Patel MR, Mahaffey KW, Garg J, Pan G, Singer DE, Hacke W, Breithardt G, Halperin JL, Hankey GJ, Piccini JP, Becker RC, Nessel CC, Paolini JF, Berkowitz SD, Fox KAA, Califf RM. Rivaroxaban versus warfarin in nonvalvular atrial fibrillation. New Engl J Med. 2011;365:883-891

[13] Connolly SJ, Ezekowitz MD, Yusuf S, Eikelboom J, Oldgren J, Parekh A, Pogue J, Reilly PA, Themeles E, Varrone J, Wang S, Alings M, Xavier D, Zhu J, Diaz R, Lewis BS, Darius H, Diener H, Joyner CD, Wallentin L. Dabigatran versus warfarin in patients with atrial fibrillation. New Engl J Med. 2009;361:1139-1151 
[14] Jung H, Yang P, Jang E, Yu HT, Kim T, Uhm J, Kim J, Pak H, Lee M, Joung B, Lip GYH. Effectiveness and safety of non-vitamin $\mathrm{K}$ antagonist oral anticoagulants in patients with atrial fibrillation with hypertrophic cardiomyopathy. Chest. 2019;155:354-363

[15] Dominguez F, Climent V, Zorio E, Ripoll-Vera T, Salazar-Men- diguchía J, García-Pinilla JM, Urbano-Moral JA, Fernández- Fernández X, Lopez-Cuenca D, Ajo-Ferrer R, SanzSanchez J, Gomez-Perez Y, López-Garrido MA, Barriales-Villa R, Gimeno JR, Garcia-Pavia P. Direct oral anticoagulants in patients with hypertrophic cardiomyopathy and atrial fibrillation. Int J Cardiol. 2017;248:232-238

[16] Noseworthy PA, Yao X, Shah ND, Gersh BJ (2016) Stroke and bleeding risks in NOACand warfarin-treated patients with hyper- trophic cardiomyopathy and atrial fibrillation. $J \mathrm{Am}$ Coll Cardiol. 2016;67:3020-3021

[17] Lee H, Kim H, Jung J, Han K, Lee H, Park J, Kim HM, Kim Y, Ommen SR. Novel oral anticoagulants for primary stroke prevention in hypertrophic cardiomyopathy patients with atrial fibrillation. Stroke. 2019;50:2582-2586

[18] January CT, Wann LS, Calkins H, Chen LY, Cigarroa JE, Cleveland JC Jr, Ellinor PT, Ezekowitz MD, Field ME, Furie KL, Heidenreich PA, Murray KT, Shea JB, Tracy CM, Yancy CW. 2019 AHA/ACC/HRS focused update of the 2014 AHA/ACC/HRS guideline for the management of patients with atrial fibrillation: a report of the American College of Cardiology Foundation/American Heart Association Task Force on Clinical Practice Guidelines and the Heart Rhythm Society. J Am Coll Cardiol. 2019;74:104-132.

[19] Creta A, Providência R, Adragao P, de Asmundis C, Chun J, Chierchia G, Defaye P, Schmidt B, Anselme F, Finlay M, Hunter RJ, Papageorgiou N, Lambiase PD, Schilling RJ, Combes S, Combes N, Albenque JP, Pozzilli P, Boveda S. Impact of Type-2 Diabetes Mellitus on the Outcomes of Catheter Ablation of Atrial Fibrillation (European observational multicentre study). Am J of Cardiol. 2020; 
[20] Calkins H, Willems S, Gerstenfeld EP, Verma A, Schilling R, Hohnloser SH, Okumura K, Serota H, Nordaby $\quad$ M, Guiver K, Biss $\quad$ B, Brouwer MA, Grimaldi M; RE-CIRCUIT Investigators. Uninterrupted Dabigatran versus Warfarin for Ablation in Atrial Fibrillation. $N$ Engl J Med. 2017;376:1627-1636.

[21] Cappato R, Marchlinski FE, Hohnloser SH, Naccarelli GV, Xiang J, Wilber DJ, Ma CS, Hess S, Wells DS, Juang G, Vijgen J, Hügl BJ, Balasubramaniam R, De Chillou C, Davies DW, Fields LE, Natale A; VENTURE-AF Investigators. Uninterrupted rivaroxaban vs. uninterrupted vitamin $\mathrm{K}$ antagonists for catheter ablation in non-valvular atrial fibrillation. Eur Heart J. 2015;36:1805-11.

[22] Kirchhof P, Haeusler KG, Blank B, De Bono J, Callans D, Elvan A, Fetsch T, Van Gelder IC, Gentlesk P, Grimaldi M, Hansen J, Hindricks G, Al-Khalidi HR, Massaro T, Mont L, Nielsen JC, Nölker G, Piccini JP, De Potter T, Scherr D, Schotten U, Themistoclakis S, Todd D, Vijgen J, Di Biase L. Apixaban in patients at risk of stroke undergoing atrial fibrillation ablation. Eur Heart J. 2018;39:2942-2955. 
Table 1. Demographics

\begin{tabular}{|c|c|c|c|c|}
\hline & $\begin{array}{c}\text { Global Sample } \\
\qquad \begin{array}{c}\mathbf{n}=137 \\
\%(\mathbf{n})\end{array}\end{array}$ & $\begin{array}{l}\text { VKA } \\
\mathbf{n}=82 \\
\%(n)\end{array}$ & $\begin{array}{l}\text { NOAC } \\
\text { n=55* } \\
\%(n)\end{array}$ & $\mathbf{P}$ \\
\hline Age & $55.0 \pm 13.4$ & $53.3 \pm 13.3$ & $57.2 \pm 13.2$ & 0.27 \\
\hline Female Sex & $29.1 \%(39)$ & $25.6 \%(21)$ & $32.7 \%(18)$ & 0.36 \\
\hline AF type at index procedure & & & & \multirow{4}{*}{0.013} \\
\hline Paroxysmal & $57.5 \%(77)$ & $40.2 \%(33)$ & $61.8 \%(34)$ & \\
\hline Persistent & $41.0 \%(55)$ & $59.8 \%(49)$ & $38.2 \%(21)$ & \\
\hline Longstanding Persistent & $1.5 \%(2)$ & $2.4 \%(2)$ & $0 \%$ & \\
\hline $\begin{array}{c}\text { Baseline ECG in Sinus Rhythm } \\
\text { - Index Procedure }\end{array}$ & $58.2 \%(78)$ & $51.2 \%(42)$ & $65.4 \%(36)$ & 0.1 \\
\hline Previous Non-AF ablation & $9.8 \%(13)$ & $9.8 \%(8)$ & $9.0 \%(5)$ & 0.71 \\
\hline $\begin{array}{c}\text { Previous Alcohol Septal } \\
\text { Ablation }\end{array}$ & $4.5 \%(6)$ & $2.4 \%(2)$ & $7.3 \%(4)$ & 0.17 \\
\hline Previous Surgical Myectomy & $10.4 \%(14)$ & $15.8 \%(13)$ & $1.8 \%(1)$ & 0.008 \\
\hline LV Apical Aneurysm & $1.5 \%(2)$ & $2.4 \%(2)$ & $0 \%$ & 0.51 \\
\hline Congestive HF & $15.7 \%(21)$ & $15.8 \%(13)$ & $14.5 \%(8)$ & 0.83 \\
\hline Hypertension & $25.4 \%(34)$ & $19.5 \%(16)$ & $32.7 \%(18)$ & 0.79 \\
\hline Diabetes & $14.2 \%(19)$ & $14.6 \%(12)$ & $12.7 \%(7)$ & 0.54 \\
\hline Stroke or TIA & $10.4 \%(14)$ & $12.2 \%(10)$ & $7.3 \%(4)$ & 0.35 \\
\hline Vascular Disease & $9.7 \%(13)$ & $8.5 \%(7)$ & $10.9 \%(6)$ & 0.64 \\
\hline Chronic Kidney Disease & $3.8 \%(5)$ & $3.6 \%(3)$ & $5.4 \%(3)$ & 0.61 \\
\hline Obstructive Sleep Apnoea & $6.7 \%(9)$ & $11 \%(6)$ & $5.4 \%(3)$ & 0.67 \\
\hline NYHA Class & $1.8 \pm 0.7$ & $1.8 \pm 0.7$ & $1.7 \pm 0.7$ & 0.91 \\
\hline $\mathrm{CHA}_{2} \mathrm{DS}_{2} \mathrm{VASc}$ & $1.5 \pm 1.5$ & $1.3 \pm 1.4$ & $1.6 \pm 1.6$ & 0.21 \\
\hline HAS-BLED & $0.8 \pm 0.9$ & $0.8 \pm 0.9$ & $0.8 \pm 0.9$ & 0.39 \\
\hline Single antiplatelet therapy & $3.6 \%(5)$ & $6.1 \%(5)$ & $0 \%$ & 0.08 \\
\hline Dual antiplatelet therapy & 0 & $0 \%$ & $0 \%$ & - \\
\hline Apical Hypertrophy & $10.9 \%(14)$ & $7.3 \%(8)$ & $10.9 \%(6)$ & 0.79 \\
\hline Moderate to Severe MR & $12.2 \%(14)$ & $7.3 \%(6)$ & $14.5 \%(8)$ & 0.17 \\
\hline Restrictive pattern & $21.6 \%(29)$ & $23.2 \%(19)$ & $18.2 \%(10)$ & 0.48 \\
\hline Max LVOT gradient $(\mathrm{mm} \mathrm{Hg})$ & $14 \pm 24$ & $9 \pm 13$ & $21 \pm 32$ & 0.02 \\
\hline Max LV Thickness (mm) & $17 \pm 4$ & $17 \pm 4$ & $18 \pm 3$ & 0.009 \\
\hline LA diameter $(\mathrm{mm})$ & $47 \pm 7$ & $49 \pm 7$ & $45 \pm 6$ & 0.5 \\
\hline LVEF & $58 \pm 9$ & $57 \pm 10$ & $59 \pm 9$ & 0.017 \\
\hline
\end{tabular}


Table 2. Type of oral anticoagulant

\begin{tabular}{|c|c|c|}
\hline & VKA & NOAC \\
& $\mathbf{n = 8 2}$ & $\mathbf{n = 5 5}$ \\
& $\mathbf{\%}(\mathbf{n})$ & $\mathbf{\%}(\mathbf{n})$ \\
\hline Warfarin & $97.6 \%(80)$ & - \\
\hline Flunidione & $2.4 \%(2)$ & - \\
\hline Apixaban & - & $32.7 \%(18)$ \\
\hline Dabigatran & - & $7.3 \%(4)$ \\
\hline Edoxaban & - & $3.6 \%(2)$ \\
\hline Rivaroxaban & - & $56.4 \%(31)$ \\
\hline
\end{tabular}

Table 3. Outcomes

\begin{tabular}{|c|c|c|c|c|}
\hline & $\begin{array}{c}\text { Global Sample } \\
\qquad \begin{array}{c}\text { n=230 } \\
\text { procedures } \\
\%(n)\end{array}\end{array}$ & $\begin{array}{c}\text { VKA } \\
\text { n=160 } \\
\text { procedures } \\
\%(n)\end{array}$ & $\begin{array}{c}\text { NOAC } \\
\text { n=70 } \\
\text { procedures } \\
\%(n)\end{array}$ & $\mathbf{P}$ \\
\hline Thromboembolism & $0.4 \%(1)$ & $0.6 \%(1)$ & $0 \%$ & 1.0 \\
\hline Stroke & $0.4 \%(1)$ & $0.6 \%(1)$ & $0 \%$ & 1.0 \\
\hline TIA & $0 \%$ & $0 \%$ & $0 \%$ & - \\
\hline Pulmonary embolism & $0 \%$ & $0 \%$ & $0 \%$ & - \\
\hline Systemic embolism & $0 \%$ & $0 \%$ & $0 \%$ & - \\
\hline Major bleeding & $5.2 \%(12)$ & $6.9 \%(11)$ & $1.4 \%(1)$ & 0.09 \\
\hline Cardiac tamponade & $3.9 \%(9)$ & $4.8 \%(7)$ & $1.4 \%(1)$ & 0.26 \\
\hline Vascular-access related & $1.3 \%(3)$ & $1.8 \%(3)$ & $0 \%$ & 0.55 \\
\hline Minor bleeding & $0.9 \%(2)$ & $0.6 \%(1)$ & $1.4 \%(1)$ & 0.54 \\
\hline Haematoma & $0.4 \%(1)$ & $0.6 \%(1)$ & $0 \%$ & 1.0 \\
\hline $\begin{array}{l}\text { Pericardial effusion not } \\
\text { requiring drain }\end{array}$ & $0.4 \%(1)$ & $0 \%$ & $1.4 \%(1)$ & 0.30 \\
\hline Other complications & $3.5 \%(8)$ & $3.1 \%(5)$ & $4.3 \%(3)$ & 0.65 \\
\hline Pneumonia & $0.4 \%(1)$ & $0.6 \%(1)$ & $0 \%$ & 1.0 \\
\hline PV stenosis & $0.4 \%(1)$ & $0.6 \%(1)$ & $0 \%$ & 1.0 \\
\hline Acute pulmonary oedema & $1.3 \%(3)$ & $1.2 \%(2)$ & $1.4 \%(1)$ & 0.91 \\
\hline Complete AV block & $0.4 \%(1)$ & $0 \%$ & $1.4 \%(1)$ & 0.30 \\
\hline Phrenic nerve palsy & $0.9 \%(2)$ & $0.6 \%(1)$ & $1.4 \%(1)$ & 0.54 \\
\hline
\end{tabular}


Table 4. Sub-analysis of outcomes in patients on uninterrupted oral anticoagulant regimen

\begin{tabular}{|c|c|c|c|c|}
\hline & $\begin{array}{c}\text { Uninterrupted } \\
\text { oral } \\
\text { anticoagulant } \\
\text { n=172 } \\
\text { procedures } \\
\%(n)\end{array}$ & $\begin{array}{c}\text { Uninterrupted } \\
\text { VKA } \\
\text { n=104 } \\
\text { procedures } \\
\%(n)\end{array}$ & $\begin{array}{l}\text { Uninterrupted } \\
\text { NOAC } \\
\text { n=69 } \\
\text { procedures } \\
\%(n)\end{array}$ & $\mathbf{P}$ \\
\hline Thromboembolism & $0.6 \%(1)$ & $1.0 \%(1)$ & $0 \%$ & 1.0 \\
\hline Stroke & $0.6 \%(1)$ & $1.0 \%(1)$ & $0 \%$ & 1.0 \\
\hline TIA & $0 \%$ & $0 \%$ & $0 \%$ & - \\
\hline Pulmonary embolism & $0 \%$ & $0 \%$ & $0 \%$ & - \\
\hline Systemic embolism & $0 \%$ & $0 \%$ & $0 \%$ & - \\
\hline Major bleeding & $4 \%(7)$ & $5.8 \%(6)$ & $1.4 \%(1)$ & 0.16 \\
\hline Cardiac tamponade & $3.5 \%(6)$ & $4.8 \%(5)$ & $1.4 \%(1)$ & 0.24 \\
\hline Vascular-access related & $0.6 \%(1)$ & $1.0 \%(1)$ & $0 \%$ & 1.0 \\
\hline Minor bleeding & $1.2 \%(2)$ & $1.0 \%(1)$ & $1.4 \%(1)$ & 0.77 \\
\hline Haematoma & $0.6 \%(1)$ & $1.0 \%(1)$ & $0 \%$ & 1.0 \\
\hline $\begin{array}{l}\text { Pericardial effusion not } \\
\text { requiring drain }\end{array}$ & $0.6 \%(1)$ & $0 \%$ & $1.4 \%(1)$ & 0.40 \\
\hline Other complications & $4.6 \%(8)$ & $4.8 \%(5)$ & $4.3 \%(3)$ & 0.88 \\
\hline Pneumonia & $0.6 \%(1)$ & $1.0 \%(1)$ & $0 \%$ & 1.0 \\
\hline PV stenosis & $0.6 \%(1)$ & $1.0 \%(1)$ & $0 \%$ & 1.0 \\
\hline Acute pulmonary oedema & $1.7 \%(3)$ & $1.9 \%(2)$ & $1.4 \%(1)$ & 0.81 \\
\hline Complete AV block & $0.6 \%(1)$ & $0 \%$ & $1.4 \%(1)$ & 0.40 \\
\hline Phrenic nerve palsy & $1.2 \%(2)$ & $1.0 \%(1)$ & $1.4 \%(1)$ & 0.77 \\
\hline
\end{tabular}

